\title{
Control of osteitis deformans using glucagon, calcitonin, and mithramycin
}

\author{
JOHN R. CONDON* \\ B.Sc., M.B., F.R.C.P.
}

\author{
JOHN SURTEES \\ M.B., M.R.C.P.E., F.R.C.Path.
}

\section{VICTOR ROBINSON \\ M.Sc.}

*Brook Hospital, London, and St Mary's Hospital, Eastbourne

\section{Summary}

Glucagon, porcine calcitonin, and mithramycin were given to patients with Paget's disease of bone. There was rapid complete relief of bone pain accompanied by biochemical improvement or normalization in all cases. Calcitonin and glucagon appear to have additive properties in Paget's disease and the use of the 3 drugs in combination may reduce the incidence of side effects and the development of 'drug resistance'. The cost of treatment might also be reduced if periodic treatment as demonstrated in Case 1 is used.

\section{Introduction}

Glucagon when given intravenously to patients with Paget's disease of bone results in relief of bone pain and a rapid fall in serum alkaline phosphatase, urinary calcium and hydroxyproline (Condon, 1971); calcitonin (Bijvoet and Jansen, 1967; Bijvoet, van der Sluys Veer and Jansen, 1968; Haddad, Birge and Avioli, 1970); and mithramycin (Ryan, Schwartze, and Perlia, 1969; Condon et al., 1971) also induces clinical and biochemical remissions in Paget's disease.

The authors treated 12 patients with various combinations of these therapeutic agents and, since all had similar responses to the therapy, 4 subjects were selected for detailed appraisal.

\section{Methods}

Serum calcium was measured by atomic absorpeo tion spectrophotometry. Serum phosphate was estimated using Technicon method $\mathrm{N}-49$ based on

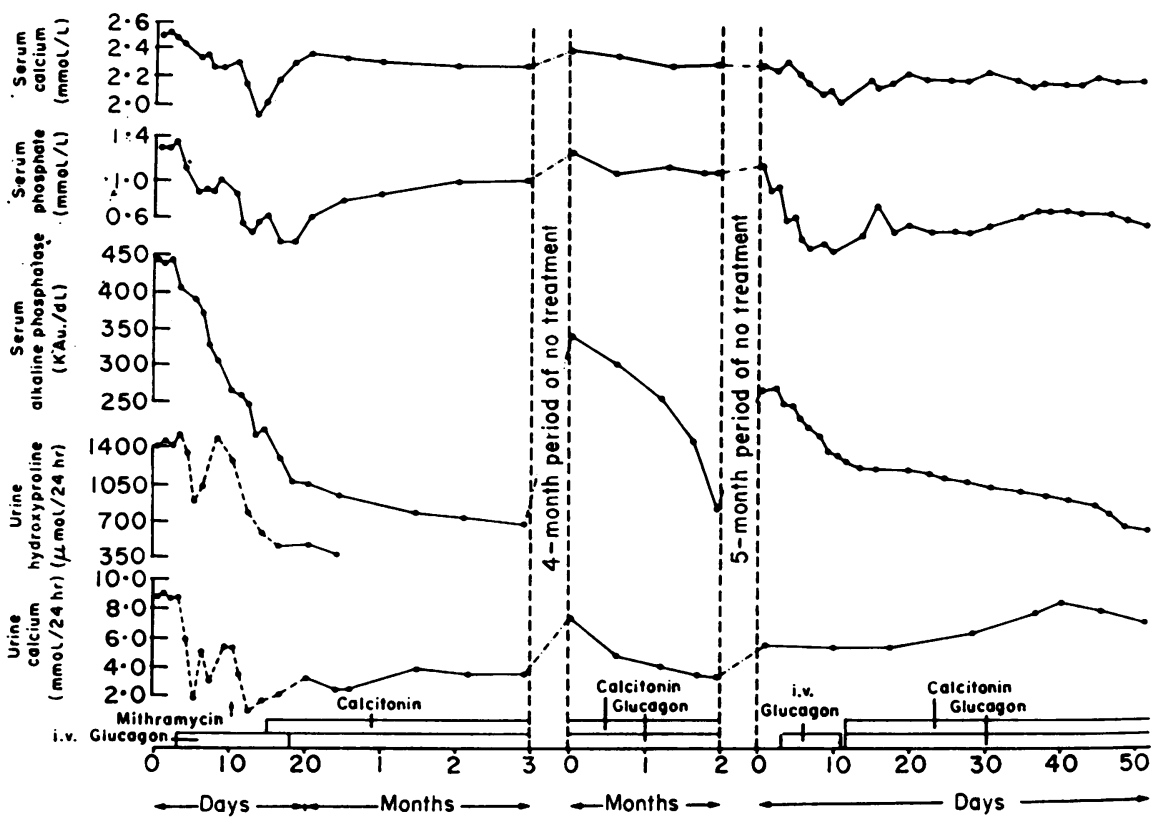

FIG. 1. Effect of glucagon, calcitonin and mithramycin on biochemical parameters in Case 1 . 
modified colorimetric determination (Fiske and Subbarow, 1925); and urinary hydroxyproline estimated using a specific assay procedure (Karl, Laitinen and Prockop, 1967).

\section{Case 1 (Fig. 1)}

This 56-year-old man presented with severe bone pain and marked facial and skull deformity.

Investigations. Serum calcium $2.46 \mathrm{mmol} / \mathrm{l}$; serum phosphate, $1.2 \mathrm{mmol} / 1$; serum alkaline phosphatase, $436 \mathrm{KAu} / \mathrm{dl}$; 24-hr urinary calcium, 8.5 $\mathrm{mmol} / \mathrm{l}$; 24-hr urinary hydroxyproline, $1526 \mu \mathrm{mol}$.

Figure 1 shows the patient's response to treatment. There was a marked fall in serum phosphate, and serum alkaline phosphatase fell to $260 \mathrm{KAu}$. after 6 days of i.v. glucagon alone. At this stage, urinary calcium was $2.35 \mathrm{mmol} / 24 \mathrm{hr}$, and urinary hydroxyproline, $1320 \mu \mathrm{mol} / 24 \mathrm{hr}$.

On day 7 of treatment, mithramycin $15 \mu \mathrm{g} / \mathrm{kg}$ was given by i.v. infusion over a period of $6 \mathrm{hr}$. Serum calcium fell to $1.95 \mathrm{mmol} / \mathrm{l}$, and serum phosphate to $0.5 \mathrm{mmol} / \mathrm{l}$. Glucagon infusion was continued during mithramycin therapy and serum alkaline phosphatase continued to fall sharply. Urinary hydroxyproline which had risen following an initial fall, dropped sharply after the mithramycin infusion: urinary calcium also fell to $1.0 \mathrm{mmol} / 1 / 24 \mathrm{hr}$. On day 11 of treatment, porcine calcitonin $2 \mathrm{u} . / \mathrm{kg}$ subcutaneously was started and 3 days later i.v. glucagon was stopped. The patient's bone pain was relieved completely by day 6 of treatment and calcitonin given alone maintained the clinical and biochemical improvement induced by glucagon and mithramycin. Twelve weeks after starting treatment, the patient felt so well that he refused further injections.

Four months later he came to Out Patients complaining of severe bone pain which had been present

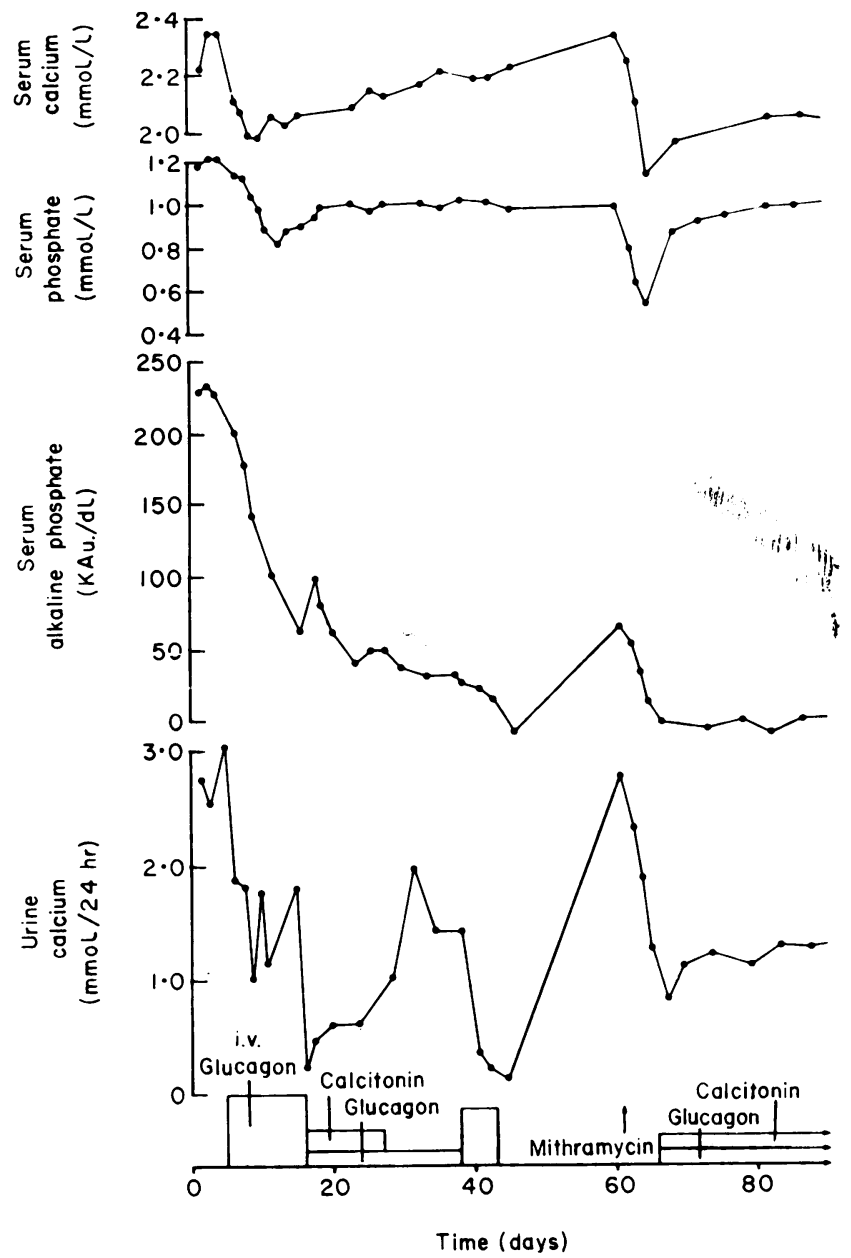

FIG. 2. Effect of glucagon, calcitonin and mithramycin on biochemical parameters in Case 2 . 
for a month. There had been a marked rise in alkaline phosphatase and urinary calcium. The dose of calcitonin the patient had previously been given was reduced by half to $80 \mathrm{u}$./day and in addition glucagon $2 \mathrm{mg} /$ day was given subcutaneously. There was relief of bone pain 2 weeks later and also a decrease in alkaline phosphatase and urinary calcium.

The patient who was now asymptomatic, failed to attend Out Patients for a second time and discontinued treatment for a period of 5 months. He sought advice again because of a recurrence of bone pain present for 4 weeks. Serum alkaline phosphatase and urinary calcium had risen but were still lower than the 2 previous peaks, the first before his initial treatment and the second after his first refusal of therapy. On this occasion, bone pain was relieved on day 6 of treatment with i.v. glucagon and serum alkaline phosphatase fell from 260 to $170 \mathrm{KAu}$./dl. With subcutaneous glucagon and calcitonin, serum alkaline phosphatase continued to fall and the $\frac{3}{2}$ patient remained asymptomatic.

Case 2 (Fig. 2)

A 64-year-old man with severe bone deformity and pain was treated with i.v. glucagon and then maintained on both calcitonin and glucagon given $\bar{\omega}$ subcutaneously for 10 days. Calcitonin was then stopped and glucagon continued alone at the same dosage for a further 10 days.

Intravenous glucagon caused an unusually marked $\vec{\circ}$ initial fall in serum calcium, together with a fall in serum phosphate, alkaline phosphatase and urinary $\vec{\omega}$ calcium. A one-day rest period was given after stopping i.v. glucagon and this was associated with a rise of alkaline phosphatase to $100 \mathrm{u}$. During the iv period which followed, subcutaneous glucagon and calcitonin were given and, as a result, serum alkaline phosphatase fell $50 \mathrm{u}$. but when calcitonin was stopped and the patient continued on glucagon alone

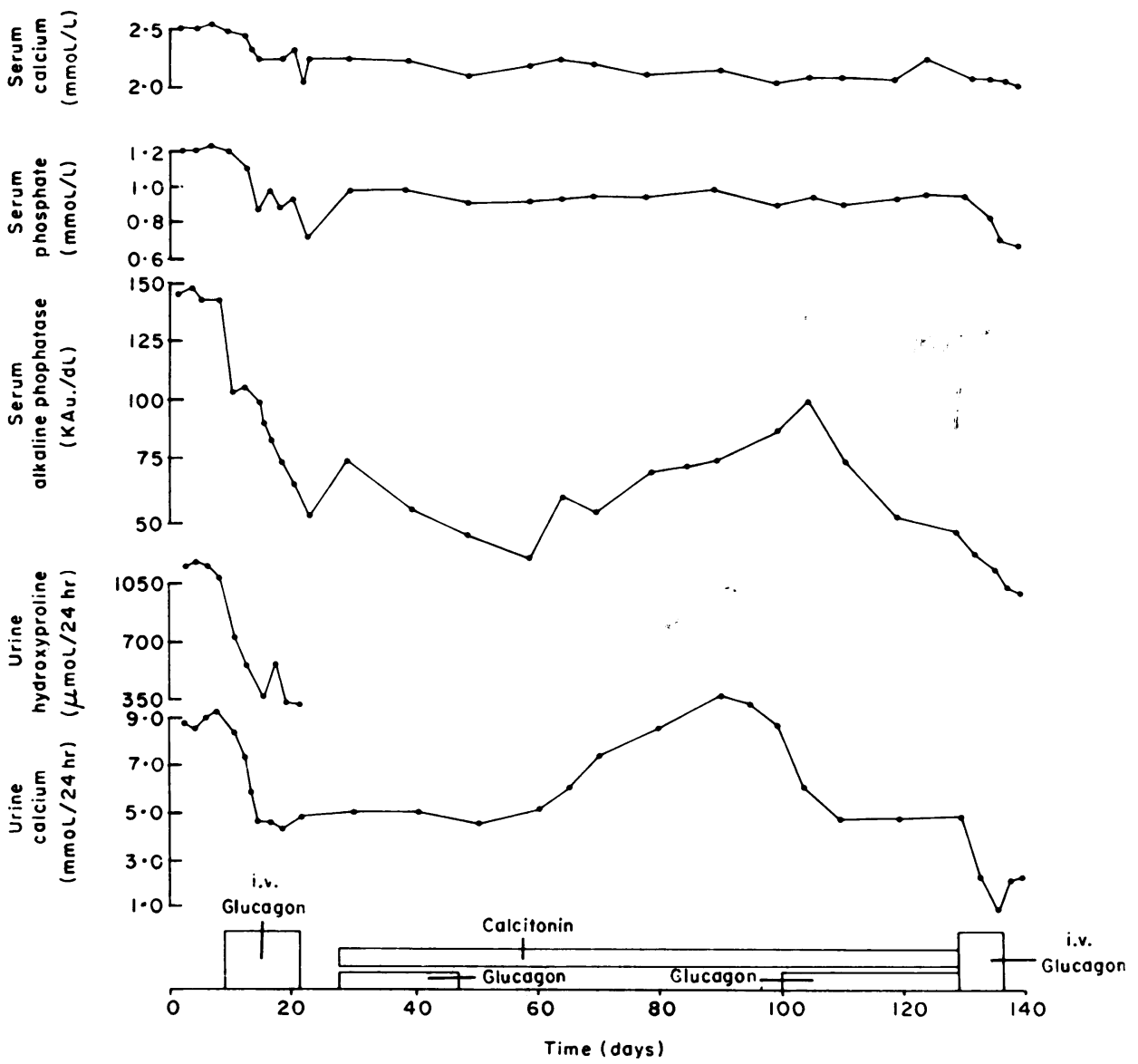

FIG. 3. Effect of glucagon and calcitonin on biochemical parameters in Case 3. 
at an unchanged dose, serum alkaline phosphatase fell only $10 \mathrm{u}$., over a similar period of time.

A further period of $1 . v$. glucagon resulted in a fall in alkaline phosphatase to normal and treatment was discontinued for 16 days. All biochemical parameters rose but rapidly returned to normal after a mithramycin infusion followed by calcitonin and glucagon subcutaneously.

\section{Case 3 (Fig. 3)}

A 69-year-old man with severe bone pain was treated initially with i.v. glucagon. There was complete relief of bone pain with a fall of serum phosphate, alkaline phosphatase, urinary calcium and hydroxyproline. Five days after stopping i.v. glucagon, treatment with subcutaneous calcitonin and glucagon was started; plasma alkaline phosphatase continued to fall until glucagon was stopped. Twelve days after stopping glucagon, when the patient was having calcitonin alone, serum alkaline phosphatase and urinary calcium began to rise; bone pain recurred and became progressively worse, but when glucagon, $2 \mathrm{mg}$ subcutaneously, was given in addition to calcitonin, bone pain was relieved within 2 weeks and both serum alkaline phosphatase and urinary calcium fell. It can be seen that the 6-day i.v. infusion of glucagon given at the 7 th week of treatment appeared to have less effect on the rate of fall of serum alkaline phosphatase than when it was given as initial treatment.

\section{Case 4 (Fig. 4)}

A 74-year-old man presented with bone pain and a sabre deformity of the left tibia. Treatment with i.v. glucagon caused a marked fall in serum phosphate, alkaline phosphatase, urinary calcium and hydroxyproline. These criteria of activity levelled out when subcutaneous calcitonin was given alone. Addition of glucagon resulted in all biochemical parameters returning to normal (Fig. 4).

\section{Discussion}

The aim of treatment of Paget's disease of bone is to relieve bone pain, prevent development of bone deformity, reduce the incidence of fractures and nerve compression, decrease hypercalciuria (which can lead to renal calculi) and control 'high output' cardiac failure by reducing blood flow through diseased bone. These criteria should be attained as rapidly as possible and calcitonin, glucagon, mithramycin and actinomycin have been used therapeutically. A 4th group of drugs, the diphosphonates, are also effective in Paget's disease of bone (Smith, Russel and Bishop, 1971; Frijlink et al., 1979) but some of these compounds may cause osteomalacia (Fleisch et al., 1970) and at the present time their use is restricted. In the authors' experience there is no

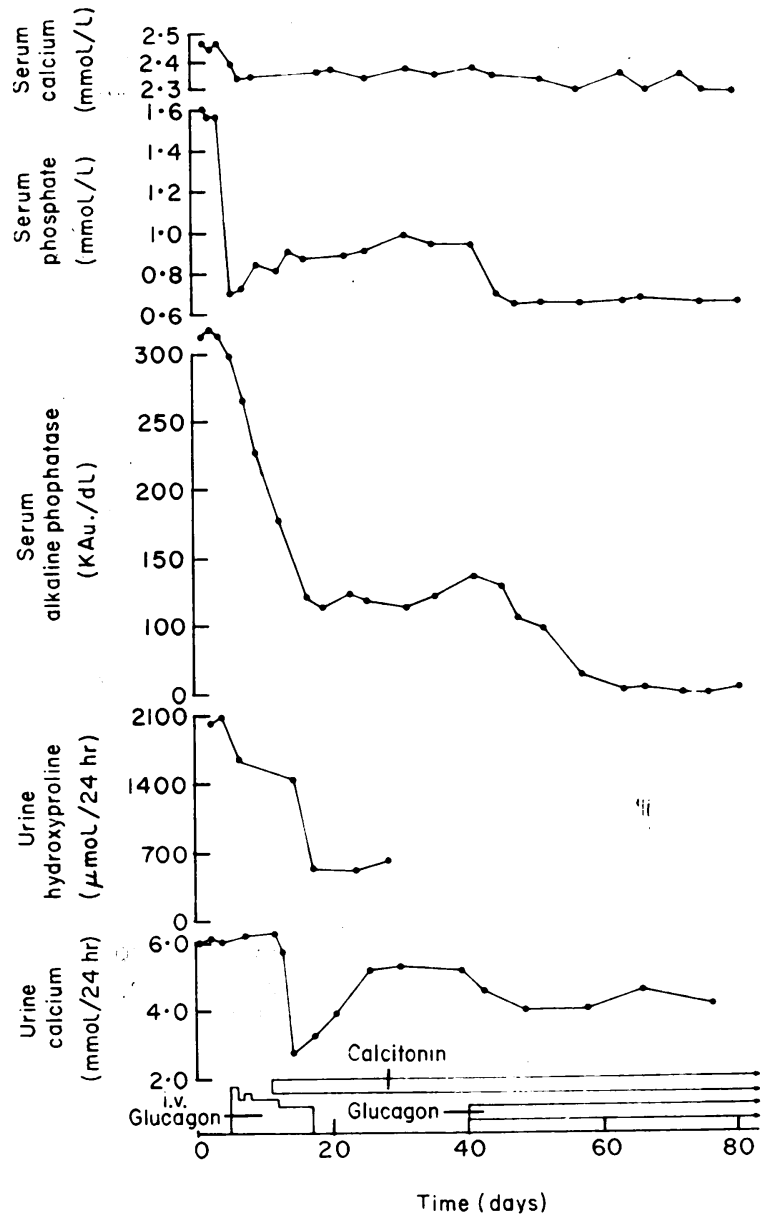

FIG. 4. Effect of glucagon and calcitonin on biochemical parameters in Case 4.

doubt that the most rapid clinical and chemical response occurs with i.v. glucagon and all their cases responded dramatically to this therapy. In Cases 1 and 3, when a second infusion of glucagon was given, biochemical response was slower than on the first occasion when the hormone was given intravenously. Indeed, in these and other subjects, treated with glucagon, the more severe the bone disorder, as reflected by a high alkaline phosphatase, the sharper the fall in this enzyme.

In Case 1, after the initial i.v. infusions were completed, subcutaneous calcitonin given alone for 11 weeks resulted in a relatively small fall in alkaline phosphatase from 108 to $90 \mathrm{u} . / \mathrm{dl}$; at the same time, urinary calcium rose. On the other hand, on a reduced dose of calcitonin together with subcutaneous glucagon these parameters fell considerably, suggesting an additive effect of the hormones. This is also well demonstrated in Cases 2 and 3. 
In the former, alkaline phosphatase fell $50 \mathrm{u}$. during treatment with glucagon and calcitonin; when the patient was given glucagon alone over a similar period, serum alkaline phosphatase fell only $10 \mathrm{u}$. In the latter, alkaline phosphatase, urinary calcium and hydroxyproline fell when glucagon and calcitonin were given together; stopping glucagon resulted in all biochemical parameters rising with a recurrence of bone pain. Re-introduction of glucagon resulted in loss of bone pain and an improvement in biochemistry.

Case 1 refused treatment for separate periods of 4 and 5 months. On the first occasion bone pain recurred at 3 months and on the 2nd occasion, 4 months after defaulting. Interestingly, although serum alkaline phosphatase had risen, peak values before initial treatment and after each default fell progressively. This finding suggests some long-term benefit of prolonged treatment. Mithramycin was given to 2 patients while they were receiving glucagon. In both instances serum calcium and phosphate fell sharply as also did urinary calcium, hydroxyproline (Case 1) and serum alkaline phosphatase.

Treatment with more than one therapeutic agent in Paget's disease may have a number of advantages. There may be fewer side effects, and the development of 'drug resistance', together with the overall cost of treatment, might be reduced. Furthermore, the various drugs employed may affect different aspects of bone metabolism, and thus complement one another.
Acknowledgment

We thank the Regional Research Committee of the South East Thames Health Authority for supporting this work.

\section{References}

BiJvoet, O.L.M. \& JANSEN, A.P. (1967) Thyrocalcitonin in Paget's disease. Lancet, ii, 471.

Bijvoet, O.L.M., Van der Sluys Veer, J. \& Jansen, A.P. (1968) Effects of calcitonin on patients with Paget's disease, thyrotoxicosis or hypercalcaemia. Lancet, i, 876.

Condon, J.R. (1971) Glucagon in the treatment of Paget's disease of bone. British Medical Journal, 4, 719.

Condon, J.R., Reith, S.B.M., Nassim, J.R., Millard, F.J.C. \& HILB, A. (1971) Treatment of Paget's disease with mithramycin. British Medical Journal, 1, 421.

Fiske, C. \& Subbarow, Y. (1925) The colorimetric determination of phosphorus. Journal of Biological Chemistry, 66, 375.

Fleisch, H., Bisaz, S., Care, A.D., Muhlbauer, R.C. \& Russell, R.G.G. (1970) A review of the effects of phosphonates on calcium metabolism. Calcitonin 1969, Proceedings of Second International Symposium, p. 409. Wm Heinemann, London.

Frijlink, W.B., Bijvoet, O.L.M., Velde, J. Te., Heynen, G. (1979) Treatment of Paget's disease with 3-amino-1hydroxypropylidene-1,1-bisphosphonate (APD). Lancet, i, 799.

Haddad, J.G., Birge, S.J. \& Avioli, L.V. (1970) Effects of prolonged thyrocalcitonin administration on Paget's disease of bone. New England Journal of Medicine, 283, 549.

KarL, I., Laitinen, O. \& Prockop, D.J. (1967) Modification of a specific assay for hydroxyproline in urine. Analytica Biochemistry, 19, 249.

Ryan, W.G., Schwartze, T.B. \& Perlia, C.P. (1969) Effect\& of mithramycin on Paget's disease of bone. Annals of Internal Medicine, 70, 549.

Smith, R., Russell, R.G.G. \& Bishop, M. (1971) Diphosphonates and Paget's disease of bone. Lancet, i, 945 . 